\title{
Self-management in patients with inflammatory bowel disease: strategies, outcomes, and integration into clinical care
}

This article was published in the following Dove Press journal:

Clinical and Experimental Gastroenterology

23 August 2016

Number of times this article has been viewed

\author{
Jill M Plevinsky' \\ Rachel N Greenley' \\ Laurie N Fishman ${ }^{2}$ \\ 'Department of Psychology, Rosalind \\ Franklin University of Medicine \\ and Science, North Chicago, IL, \\ 2Department of Gastroenterology, \\ Boston Children's Hospital, Harvard \\ Medical School, Boston, MA, USA
}

Correspondence: Jill M Plevinsky Department of Psychology, Rosalind Franklin University of Medicine and Science, 3333 Green Bay Road, North Chicago, IL 60064, USA

Tel + I 847578875 I

Fax + I 8475788765

Email jill.plevinsky@my.rfums.org

\begin{abstract}
Self-management, including medication adherence, is associated with improved health and outcomes for patients with inflammatory bowel disease. The concept of self-management is complex, but can be divided into those aspects that involve the individual patient, those that involve the provider-patient relationship, and those that encompass the social environment. At the individual level, enhancing problem-solving skills and self-efficacy have both been shown to improve self-management tasks, particularly adherence to treatment. However, it is critical to consider these domains from a lifespan perspective because these processes by which selfmanagement can be improved are distinct for children, adolescents, young adults, and adults. A particular emphasis is placed on strategies to improve self-management of older adolescents and young adults as they transition from pediatric to adult providers. The review concludes with recommendations for providers, including rationale and techniques for assessing and promoting patient self-efficacy, encouraging the development of problem-solving skills, improving the patient-provider relationship, and enhancing social support. Providers are encouraged to utilize elements of problem-solving skills training, engage in collaborative relationships with their patients, and offer their patients recommendations for how to increase the quality of their social support networks as ways of increasing overall self-management.
\end{abstract}

Keywords: adherence, self-efficacy, communication, social support, Crohn's disease, ulcerative colitis

\section{Introduction}

Inflammatory bowel diseases (IBDs) are idiopathic, chronic, and autoimmune illnesses affecting the digestive system. IBD presents in 71 of every 100,000 youth and 439 of every 100,000 adults in the US. ${ }^{1}$ Over 1 million residents in the US and 2.5 million in Europe are estimated to have IBD. ${ }^{2}$ IBD has begun to emerge in newly industrialized countries in Asia, South America, and the Middle East as well, with prevalence rates rising exponentially on every continent now classifying IBD as a global disease. The highest prevalence rates are found in the Western world with a higher prevalence of ulcerative colitis in Europe, a higher prevalence of Crohn's disease in Australia, and lower overall prevalence of IBD in Mediterranean and Eastern European countries. ${ }^{2}$

IBD is comprised of various pathologies, including Crohn's disease, ulcerative colitis, and indeterminate colitis, or IBD-unspecified. There is a slight female predominance in Crohn's disease, especially among women in late adolescence and early adulthood, while pediatric cases of Crohn's disease tend to exhibit a male predominance. ${ }^{2}$ These two conditions are most commonly diagnosed in late adolescence 
and early adulthood, although rates of diagnosis in young children and adolescents are increasing worldwide due to the industrialization of diverse geographic regions and advances in awareness and detection. ${ }^{3,4}$

Ongoing management of IBD can include daily oral medications, weekly or biweekly subcutaneous injections, or periodic infusions, in addition to surgical procedures, routine endoscopic screenings, and various lifestyle modifications (eg, dietary restrictions). Each patient may be prescribed a different combination of the previously mentioned treatments, which renders self-management in IBD particularly challenging to both assess and improve with structured interventions. Difficulties with self-management, documented in both pediatric and adult patients with IBD, are often associated with poorer mental and physical health outcomes..$^{5-8}$ In contrast, effective self-management can improve disease outcomes as measured by fewer symptoms, fewer hospitalizations, and less need for medical treatment escalation. ${ }^{7}$

While conceptualizations of self-management vary, the construct generally refers to the daily activities that individuals must perform to keep their illness under control, minimize its impact on their physical health and functioning, and cope with any comorbid or resulting psychological symptoms. ${ }^{8}$ Medication adherence is a well-studied core component of self-management. Most self-management conceptualizations also acknowledge the role of the environment (eg, family, social context) in either facilitating or interfering with disease management behaviors. ${ }^{9}$ In addition to the domains of the individual patient and their social context, the health care system or patient-provider relationship add another dimension to be considered when assessing and improving self-management.

Given the importance of effective self-management for optimal disease outcomes, attention has been directed toward interventions to enhance individual patient self-management. These interventions involve educational programs to enhance health literacy, behavior modification to improve lifestyle choices, and disease-specific skill development (eg, awareness of signs or symptoms of activity disease flare, knowing the function of their treatment(s), knowing how to refill a prescription, or knowing how to schedule a medical appointment). Additional strategies include coping skills training such as relaxation training and enhancing patient empowerment. ${ }^{7}$ Since successful self-management involves self-regulation and problem-solving, ${ }^{10,11}$ it is important to foster both patient self-efficacy and problem-solving skills. Successful self-management can be enhanced by learning to confidently and effectively use problem-solving skills to address self-identified difficulties. ${ }^{12}$ This paradigm of selfmanagement allows patients to benefit from a sense of control over their lives and their disease rather than feeling that the disease is in control, ${ }^{7}$ and in tandem, fosters collaborative care between patients and providers.

At the health care systems level, the patient-provider relationship is essential for successful disease self-management. According to the Chronic Care Model, ${ }^{13}$ "optimal chronic illness care is achieved when a prepared, proactive practice team interacts with an informed, activated patient". In other words, in order to best support self-management of a chronic illness, the patient-provider relationship ought to be a partnership between activated patients and proactive providers. ${ }^{14}$ Across chronic illness populations, the patientprovider relationship and satisfaction with patient-provider communication have been implicated as a contributor to whether a patient demonstrates successful self-management in the form of medication adherence, attending appointments, and engaging in a healthy lifestyle, in both pediatric and adult populations. ${ }^{15-17}$

Social support is another relevant domain of selfmanagement of a chronic illness because self-management does not exist in a vacuum, but rather in a context of both an individual's social network, in particular, their families and communities. In a review of social support interventions and their impact on self-management, six of nine studies found a significant positive relationship between the two domains, and an additional six studies found partial support for the idea that social support is positively related to self-management. ${ }^{9}$ Social factors have also been identified as significant barriers to adherence to treatment in youth with IBD. ${ }^{18}$

It is important to recognize how the roles of these three domains in contributing to successful self-management are distinct for individuals at different developmental stages (eg, young children, adolescents and young adults [YA], middle aged, and older adults). For example, younger children rely on their parents to assist them in problem solving, navigating their relationship with their physician, and for social support. Children under the age of 12 show better self-management outcomes (eg, higher medication adherence) when compared with teenagers, ${ }^{19}$ which may be due, in part, to higher levels of family involvement in their care. Children and adolescents also require social support to enhance their quality of life, ability to cope with their diagnosis, adjustment to changes in their appearance caused by medication, and coping skills. ${ }^{20}$ In contrast, adults are largely responsible for themselves in all of these areas and may rely more heavily on a spouse or peer forms of support. Self-management interventions for 
adults with IBD have been found to have a moderate influence on health-related quality of life, and specifically, distance self-management programs (eg, telemedicine, web-based intervention) appear to have the potential to produce better outcomes in this population. ${ }^{21,22}$

The period of adolescence and young adulthood is a unique developmental time, which is characterized by substantial variability in terms of how much adolescents and YA are responsible for their own self-management. Research on self-management in older adolescents and young adults (OA/ YA) with chronic conditions suggests that this age group is at particular risk of poor self-management. Specifically, OA/YA with IBD are at greater risk of poor adherence relative to their younger counterparts, ${ }^{19}$ a finding that has been documented among YA in the general population, ${ }^{23}$ as well as YA affected by other chronic medical conditions such as type 1 diabetes, asthma, and cancer. ${ }^{24-26}$

College students with IBD are described as having particular difficulty with self-management as a function of the transition to college. A qualitative study of college students with IBD revealed that perceived readiness (eg, ability to adapt), aspects of their interactions with their providers (eg, anticipatory guidance), and the nature of their social network contributed to the nature of their experience transitioning to college life. College can be a "proving ground" for demonstrating good self-management, and OA/YA with IBD need to receive support focused on developing practical ways to address challenges, working with their providers to optimize their health, and developing strategies to seek psychosocial support. ${ }^{27}$

The processes of transition and transfer of care to an adult provider further complicate this developmental stage and contribute added demands, and barriers, to optimal selfmanagement. OA/YA with IBD are at risk of becoming lost to follow-up as they transfer from pediatric to adult care. Adherence to medical treatment is variable as OA/YA become solely responsible for their own disease management. Adult gastroenterologists are reported to perceive adolescents as poorly prepared to manage their own care. ${ }^{28}$ Therefore, it is important that transition and transfer to adult care occur in a structured way in this population, whether through joint clinics, transition clinics, transition coordinators, or other constructs. Special attention to self-management challenges during this period is warranted.

The following descriptive review of the literature on selfmanagement in IBD will include self-management trials and research efforts designed to assess the following modifiable skill or support domains, which as illustrated, are associated with self-management in this population: 1) patient selfefficacy and problem-solving skills; 2) the patient-provider relationship and communication; and 3) the social support available to the patient from significant others in their lives. However, the development of interventions addressing these mechanisms of improving self-management varies. Therefore, the present review will cover the research as it stands with the goal of outlining areas for improvement as well as areas for future intervention. Additionally, recommendations for integration of self-management promotion strategies into clinical care will be outlined for children and adolescents, $\mathrm{OA} / \mathrm{YA}$, and middle aged and older adults.

\section{Enhancing self-efficacy and problem-solving skills}

Self-management interventions targeting self-efficacy and problem-solving skills have primarily focused on enhancing medication adherence for patients with IBD based on the descriptive work enumerating both cognitive and organizational barriers to adherence (eg, forgetting, being away from home, interference with activity). ${ }^{5,29-31}$ Self-efficacy refers to a person's ability to implement situation-specific behaviors in order to attain established goals or desired outcomes. ${ }^{32}$ In the context of a chronic medical condition, such as IBD, disease self-efficacy refers to an individual's perception of his or her ability to organize and execute the behaviors necessary to manage their disease. ${ }^{33}$ Problem-solving skills training (PSST) is a widely utilized approach to promoting both disease management self-efficacy and medication adherence, and research supports that it is useful as a stand-alone intervention among youth with IBD. ${ }^{30}$ Moreover, PSST is commonly incorporated into multicomponent adherencepromotion interventions for pediatric and adult IBD populations. ${ }^{5,31}$ PSST involves teaching individuals a systematic way of identifying the unique barriers to adherence that they experience and skills for implementing a structured plan to generate, implement, and evaluate the successfulness of solutions to these barriers. PSST interventions, because they are customizable to the unique barriers experienced by an individual, have the potential to address both intentional and accidental forms of nonadherence. ${ }^{33-36}$ Moreover, the skill set can be generalized to other domains of self-management difficulties.

Multiple pediatric studies have provided empirical support for PSST interventions. ${ }^{37-41}$ Among youth with IBD, a two-session family-based PSST intervention trial documented a $10 \%$ improvement in adherence among youth with imperfect adherence from pre- to postintervention. Moreover, 
improvements in quality of life were also documented from pre- to postintervention. In other pediatric groups, including youth with epilepsy, cystic fibrosis, diabetes, and traumatic brain injuries, PSST has also been shown to enhance key aspects of self-management including adherence. . $^{3739-41}$

Among adults with IBD, PSST has been shown to improve treatment adherence. Cook et al conducted an intervention in which a nurse delivered elements of PSST to adults with ulcerative colitis. ${ }^{42}$ Results suggested that self-efficacy predicted treatment adherence, and adherence improved over the course of the intervention. Therefore, one mechanism by which PSST may positively impact self-management skills is via enhancing self-efficacy. Increased levels of self-efficacy as well as enhanced problem-solving skills and higher levels of treatment adherence are intermediate measures of improved health outcomes and hold the most promise for future research and development of interventions to improve self-management in general. ${ }^{43}$

\section{Optimizing the patient-provider relationship and communication}

The patient-provider relationship is complex, and impairments in this relationship including mistrust, dishonesty, or general discomfort during patient-provider conversations have been shown to correlate with nonadherence. ${ }^{44,45}$ Specifically in patients with IBD, poorer communication as reflected by higher discordance with the physician, increases risk of nonadherence, even in those without psychological distress. ${ }^{46}$ A high quality patient-provider relationship requires collaboration and a shared commitment to the treatment plan. This collaboration, or concordance, needs to involve empathy and shared decision making in order to positively influence a patient's self-management. ${ }^{8}$ YA with IBD who reported a positive relationship with their adult providers also endorsed more collaborative decision making and patients who report high levels of concordance with their physicians are more likely to report better adherence to their treatment. ${ }^{47,48}$ Additionally, when providers engaged in shared decision making with caregivers of youth with asthma, caregivers reported higher rates of medication adherence. ${ }^{49}$

The quality of communication between patient and provider has implications for self-management. High quality patient-provider communication is critical for adult patients, but it is especially critical for pediatric patients and their families. In particular, research shows that parents who reported better interactions and communication with their child's provider were more likely to instruct their children to adhere to their treatment plan. ${ }^{50}$ While there is limited research on how effective communication between patients and providers impacts adherence in the context of IBD, overall, patients who report poor communication with their providers have been found to have a $19 \%$ higher risk of nonadherence than those reporting good communication. ${ }^{44}$

Interventions that attempt to improve patient-provider relationship across chronic illness populations have taken various forms, including email communications with providers, written educational material, and follow-up reminders. Despite variability in methodology, all interventions have targeted improving self-management through enhancing aspects of the patient-provider relationship and communication, and the data support that these improvements may have potential benefit to self-management. In the context of IBD, research to date has focused on assessing the benefits of email communication. A recent review of the research regarding email communication with providers in the context of IBD suggest that its potential to complement self-management has many benefits, including efficiency, convenience, fewer hospital visits, improved quality of life, and reduced anxiety. ${ }^{51,52}$ Additionally, experienced physicians can effectively assess a patient's needs by symptom disclosure via email. ${ }^{7}$ When surveyed, 90\% of patients endorsed a preference for clinic visits combined with email access to their physicians, therefore, adopting email communication as a part of patient care may be beneficial for patient self-management. ${ }^{52}$

\section{Increasing quality and utility of social support}

Social support has been documented as a factor associated with self-management in both pediatric and adult populations. Specifically, evidence suggests that illness-specific support may have a stronger relationship to self-management than general social support, ${ }^{9}$ and practical social support (eg, assistance, reminders, organization, and support for a specific behavior) in particular is most associated with treatment adherence. ${ }^{53}$

In adults with IBD, whom are often responsible for their own self-management, significant others tend to be a strong source of social support, with families and peers as secondary sources, ${ }^{9}$ and lower perceived social support is associated with decreased health-related quality of life and a greater number of relapses. ${ }^{54}$ However, youth with IBD often rely on their parents to perform the same self-management tasks even during college years. ${ }^{55}$ Parents tend to serve as an important source of social support for youth with IBD, and research confirms that parental involvement in condition management is associated with better adherence. ${ }^{56}$ Additionally, parents 
of youth with IBD tend to report lower levels of social support for themselves than parents of children without chronic conditions. Notably, these lower levels of social support tend to be associated with increased parent psychological distress, which also has the potential to impede a parent's ability to manage their child's chronic condition. ${ }^{57}$

Among adolescents and YA, social support from both family and friends is associated with improved ability to cope with IBD ${ }^{58}$ Conversely, peer victimization has been associated with lower treatment adherence in adolescents with IBD. ${ }^{59}$ Therefore, it is important to assess the possible role that positive and negative peer interactions play in adolescents with IBD, as it may affect patterns of self-management. Stigma is also a salient concern for adolescents and YA with IBD. Specifically, adolescents and adults report that stigma surrounding the symptoms of IBD often leads to social isolation and concealment of difficulties coping with those symptoms. ${ }^{60,61}$ Internalized stigma, or internalized shame or sense of loss of self, may reduce a patient's motivation to engage in optimal self-management, thereby impacting both adherence and clinical outcomes. ${ }^{62}$

A number of studies have attempted to improve selfmanagement via enhancing opportunities for social support. For example, among adults with IBD, interventions aimed at increasing social support often decreased a patient's psychological distress, which in turn facilitated better selfmanagement. ${ }^{46}$ In other illness populations, such as type 2 diabetes, social support interventions have been shown to improve self-management behaviors as well as health outcomes, including weight loss and better metabolic control. ${ }^{63}$

As the literature stands, there is little empirical evidence regarding the mechanisms of social support interventions, or how well they work in the context of IBD; however, they can be useful overall. Enhanced patient self-efficacy may be one mechanism by which social support positively influences self-management in chronic illness management. ${ }^{9}$ In fact, research from several distinct patient populations, including adults with HIV, sedentary overweight adults, and patients with diabetes, suggests that higher levels of social support are either directly or indirectly related to greater self-efficacy for disease management and more positive self-management outcomes. ${ }^{64-66}$ In other words, an individual's social network may be influential in bolstering their self-efficacy, which in turn improves their self-management.

Social support in patients with IBD can also be enhanced through education about the influence of social support, through the use of the Internet and through self-help groups. ${ }^{67}$ Young patients can even have the opportunity to attend Camp
Oasis, a weeklong camp for children and adolescents with IBD, which emphasizes social support. Camp Oasis has been shown to increase self-reported social support, and this increase was maintained after youth participated in a Facebook group after the camp session had concluded ${ }^{68}$ Other benefits of Camp Oasis have been documented with regards to health-related quality of life ${ }^{69}$ and overall psychosocial adjustment. $^{70}$

Group interventions that provide support through family and friends utilize a patient's natural support system and tend to have positive outcomes. These interventions tend to involve behavioral training of family members or friends, but some include group problem solving as well. Peer support groups have also been found to be generally beneficial to those involved, such as self-help groups and professionally led support groups. ${ }^{71}$ Social skills training group interventions also have the potential to improve one's relationship and better benefit from their natural support system. ${ }^{72}$ Overall, friends and family play a significant role in chronic illness self-management, and interventions to address self-management ought to include the patient's own social network in order to better influence health, functional, and psychosocial outcomes. ${ }^{9}$

\section{Recommendations for clinical practice}

The present review explored previous literature investigating self-management in IBD across the lifespan with an emphasis on the following processes, which seem to theoretically and anecdotally have the largest impact on the construct: selfefficacy and problem-solving skills, the patient-provider relationship and social support. The aim of the review was to adopt a novel conceptualization of self-management that focused on these possible mechanisms for improving selfmanagement in patients with IBD of all ages.

Self-efficacy predicts self-management better than education alone, which is why providers need to do more than just promote health literacy in their patients. ${ }^{33}$ Providers can assess self-efficacy with brief standardized measures that have been developed for use with patients with IBD. ${ }^{34,73}$ Patient self-efficacy can be enhanced through supportive counseling by a member of the health care team with the goal of helping the patient remain engaged in their health and build confidence in their ability to adhere to their selfmanagement plan. ${ }^{74}$ For YA/OA, especially those preparing to transition to adult care, a technology-based intervention may be more appropriate. ${ }^{22}$ Providers can enhance self-efficacy based on Bandura's theory that self-efficacy is comprised of 
previous successful self-management, vicarious experiences or modeling successful self-management, verbal persuasion (eg, suggestion), and anxiety. ${ }^{75}$ Specifically, in order to improve self-management by enhancing self-efficacy, the health care team should emphasize and positively reinforce previous periods of successful self-management. Providers should also engage the patient's family members in modeling successful self-management and use the power of suggestion to empower patients to feel that they have the ability to adhere to their treatment plan. Finally, the health care team ought to assess for heightened level of anxiety in their patients and provide them with resources or coping skills to manage this barrier to optimal self-efficacy. ${ }^{76}$

Providers can encourage the development of problemsolving skills through helping their patients to identify barriers to self-management and collaboratively helping them to come up with solutions to these barriers. ${ }^{77,78}$ Adults typically have better developed problem-solving skills that allow them to adjust to self-management routines better than children or adolescents but may still benefit from working through any barriers to self-management with their health care team. ${ }^{20}$ Brief clinic-based problem-solving training delivered by health care providers has been implemented in other patient populations, ${ }^{37,79}$ suggesting that this may be a feasible option in patients with IBD. Specifically, providers could implement aspects of the interventions with their patients with IBD by promoting positive problem orientations in their patients. That is, providers should assess whether negative emotions (eg, anxiety, depression) are impeding problem-solving abilities, promote positive emotions and a sense of competency to facilitate problem-solving, and motivate their patients to solve these problems. ${ }^{80}$ Taking into account the differences in social support networks across the lifespan, intervention should assess for those influential individuals in a patient's network (eg, parents, peers, children) and involve them in the problem-solving interventions to ensure that the solutions are practical and easily implemented.

Improving patient-provider communication is important in both pediatric and adult IBD care. To reduce family conflict in youth with IBD, which has been associated with poorer self-management, providers ought to collaborate with both the parent and the child when discussing changes in responsibility for self-management. ${ }^{56}$ In a descriptive study of adolescents with type 1 diabetes and their parents, themes related to issues with illness management included frustration, fear, normalizing, trusting, and discounting. Specifically, parents found it difficult to trust their children with management, and this difficulty was associated with frustration, fear, and discounting communication. Therefore, clinicians may play an important role in facilitating trust and positive parent-child communication about illness management. ${ }^{81}$ Additionally, the openness of patient-provider communication is especially important for OA/YA as they begin to take on more responsibility for their care and transition from pediatric to adult care. OA/YA who reported having a better experience with their pediatric providers were more likely to bring up confusion regarding medical decisions with their adult providers posttransfer. ${ }^{47}$

Collaborative decision making and satisfaction with the patient-provider relationship and communication are also necessary for adult patients, especially as in most cases, they are solely responsible for their self-management. In adults with chronic conditions, the decision to not adhere to their treatment may be a rational choice from their own point of view, which is why cooperative patient-provider relationships and effective communication are keys in helping them to fully understand the rationale for their self-management plan. ${ }^{73}$ Physicians can improve their relationship and communication with their patients by utilizing the acronym COPE (communicating; obtaining commitment to therapeutic goals; promoting emotional, psychological, and physical support; and educating the patient and their family). ${ }^{8} \mathrm{~A}$ patient-centered approach to care (eg, asking open-ended questions, picking up cues from patients, clarification, summarizing, and collaboration) in which patients negotiate and collaborate with their providers to develop self-management plans is another way of enhancing the patient-provider relationship. ${ }^{52}$

Providers ought to assess their patients' social support systems and aid in enhancing already existing sources of social support to bolster optimal self-management. There are various validated measures of social support, some of which focus on the size of one's social support network while others such as the Social Support Questionnaire assess satisfaction with support. ${ }^{9,82}$ As discussed, specific sources of support may vary with the age of the patient. Providers should take each individual patient's social environment into account and not only acknowledge their social context, but understand that social influences can be positive or negative. For example, adults enrolled in a support group for people with Ménière's disease reported varying directions of social comparison (eg, upward, downward, lateral). ${ }^{83}$ This suggests that support groups can be positive, neutral, or negative influences on participants; however, it is difficult to predict how patients will perceive those who have more or less severe disease and whether that impedes that positive effects of participation in a support group. Providers do have the ability to empower 
individuals to manage their social support networks so that the patient can utilize adaptive sources of social support in their lives in order to foster successful self-management behaviors. ${ }^{9}$ Empirically evaluated support groups, camps, and websites can also provide social support resources for pediatric and adult patients with IBD. ${ }^{46,84}$

\section{Conclusion}

Overall, physicians and IBD health care providers can play an important role in improving self-management in their patients by enhancing their ability to manage their condition with positive reinforcement and PSST. Attending to the nature of their relationship and the quality of their communication with their patients of all ages are also critical. Evaluating a patient's social support structure, and offering ways for patients with IBD to connect with other patients through social support programming, may be helpful for increasing self-management both directly and indirectly via enhanced self-efficacy.

While these strategies do involve time and effort on the part of the health care team, research suggests that it is possible to successfully deliver interventions aimed at improving treatment adherence and overall self-management. ${ }^{85}$ There are many ways by which various members of the health care team could incorporate self-management promoting interventions as a component of care including utilizing multiple members of the interdisciplinary team as well as telecommunication or email.

\section{Disclosure}

The authors report no conflicts of interest in this work.

\section{References}

1. Kappelman MD, Rigas-Shiman SL, Kleinman K, Ollendorf D, Bousvaros A, Grand RJ, Finkelstein JA. The prevalence and geographic distribution of Crohn's disease and ulcerative colitis in the United States. Clin Gastroenterol Hepatol. 2007;5(12):1424-1429.

2. Kaplan GG. The global burden of IBD: from 2015 to 2025. Nat Rev Gastroenterol Hepatol. 2015;12(12):720-727.

3. Loftus E. Clinical epidemiology of inflammatory bowel disease: incidence, prevalence, and environmental influences. Gastroenterology. 2004;126(6):1504-1517.

4. Gasparetto M, Guariso G. Highlights in IBD epidemiology and its natural history in the paediatric age. Gastroenterol Res Pract. 2013;2013:829040.

5. Hommel KA, Greenley RN, Maddux MH, Gray WN, Mackner LM. Selfmanagement in pediatric inflammatory bowel disease: a clinical report of the North American Society of Pediatric Gastroenterology, Hepatology, and Nutrition. J Pediatr Gastroenterol Nutr. 2013;57(2):250-257.

6. Smolen DM, Topp R. Self-care agency and quality of life among adults diagnosed with inflammatory bowel disease. Qual Life Res. 2001;10(4):379-387.

7. Saibil F, Lai E, Hayward A, Yip J, Gilbert C. Self-management for people with inflammatory bowel disease. Can J Gastroenterol. 2008;22(3):281-287.

8. Robinson A. Review article: improving adherence to medication in patients with inflammatory bowel disease. Aliment Pharm Ther. 2008;27(Suppl 1):9-14.
9. Gallant MP. The influence of social support on chronic illness selfmanagement: a review and directions for research. Health Educ Behav. 2003;30(2):170-195.

10. Modi AC, Pai AL, Hommel KA, et al. Pediatric self-management: a framework for research, practice and policy. Pediatrics. 2012;129(2):e473-e485.

11. Barlow J, Wright C, Sheasby J, Turner A, Hainsworth J. Self-management approaches for people with chronic conditions: a review. Patient Educ Couns. 2002;48(2):177-187.

12. Barlow C, Cooke D, Mulligan K, Beck E, Newman S. A critical review of self-management and educational interventions in inflammatory bowel disease. Gastroenterol Nurs. 2010;33(1):11-18.

13. Flandt $\mathrm{K}$. The chronic care model: description and application for practice. J Adv Pract Nurs. 2006;6(4):1-8.

14. Bodenheimer T, Lorig K, Holman H, Grumbach K. Patient self-management of chronic disease in primary care. JAMA. 2002;288:2469-2475.

15. Bodenheimer $\mathrm{T}$, Wagner $\mathrm{EH}$, Grumbach $\mathrm{K}$. Improving primary care for patients with chronic illness. JAMA. 2002;288:1775-1779.

16. Litt IF, Cuskey WR. Satisfaction with health care: a predictor of adolescents' appointment keeping. J Adolesc Health Care. 1984;5(3):196-200.

17. Hazzard A, Hutchinson SJ, Krawiecki N. Factors related to adherence to medication regiments in pediatric seizure patients. J Pediatr Psychol. 1990;15(4):543-555.

18. Hommel KA, Baldassano RN. Brief report: barriers to treatment adherence in pediatric inflammatory bowel disease. J Pediatr Psychol. 2010;35(9):683-691.

19. LeLeiko NS, Lobato D, Hagin S, et al. Rates and predictors of oral medication adherence with pediatric IBD. Inflamm Bowel Dis. 2013;19(4):832-839.

20. Mamula P, Markowitz J, Baldassano R. Inflammatory bowel disease in early childhood and adolescence: special considerations. Gastroenterol Clin North Am. 2003;32(3):967-995.

21. Tu W, Xu G, Du S. Structure and content components of self-management interventions that improve health-related quality of life in people with inflammatory bowel disease: a systematic review, meta-analysis and meta-regression. J Clin Nurs. 2015;24(19-20):2695-2709.

22. Huang J, Terrones L, Tompane T, et al. Preparing adolescents with chronic disease for transition to adult care: a technology program. Pediatrics. 2014;133(6):e1639-e1646.

23. Neinstien LS, Irwin CE. Young adults remain worse off than adolescents. J Adolescent Health. 2013;53(5):559-561.

24. Dashiff C, Vance D, Abdullatif H, Wallander J. Parenting, autonomy and self-care of adolescents with type 1 diabetes. Child Care Health Dev. 2008;35(1):79-88.

25. Bender BG. Risk taking, depression, adherence, and symptom control in adolescents and young adults with asthma. Am J Respir Crit Care Med. 2006;173:953-957.

26. Butow P, Palmer S, Pai A, Goodenough B, Luckett T, King M. Review of adherence-related issues in adolescents and young adults with cancer. J Clin Oncol. 2010;28(32):4800-4809.

27. Schwenk HT, Lightdale JR, Arnold JH, Goldmann DA, Weitzman ER. Coping with college and inflammatory bowel disease: implications for clinical guidance and support. Inflamm Bowel Dis. 2014;20(9):1618-1627.

28. Fishman L, Barendse RM, Hait E, Burdick C, Arnold J. Self-management of older adolescents with inflammatory bowel disease: a pilot study of behavior and knowledge as a prelude to transition. Clin Pediatr. 2010;49(12):1129-1133.

29. Robinson A, Thompson DG, Wilkin D, Roberts C; Northwest Gastrointestinal Research Group. Guided self-management and patientdirected follow-up of ulcerative colitis: a randomized trial. Lancet. 2001;358(9286):976-981.

30. Greenley RN, Nguyen E, Kunz JH, et al. Phone intervention to improve pediatric oral medication adherence: preliminary acceptability and feasibility. Inflamm Bowel Dis. 2011;17:S12-S57.

31. Greenley RN, Kunz JH, Walter J, Hommel KA. Practical strategies for enhancing adherence to treatment in inflammatory bowel disease. Inflamm Bowel Dis. 2013;19(7):1534-1545. 
32. Bandura A. Self-efficacy: The Exercise of Control. New York, NY: W.H. Freeman and Company; 1997.

33. Nezu AM, Nezu CM, Perri MG. Problem solving to promote treatment adherence. In: O’Donohue WT, Levensky ER, editors. Promoting Treatment Adherence: A Practical Handbook for Health Care Providers. Thousand Oaks, CA: Sage Publications, Inc; 2006:135-148.

34. Keefer L, Kiebles, JL, Taft TH. The role of self-efficacy in inflammatory bowel disease management: preliminary validation of a disease-specific measure. Inflamm Bowel Dis. 2011;17(2):614-620.

35. Elliott TR, Grant JS, Miller DM. Social problem-solving abilities and behavioral health. In: Chang EC, D'Zurilla TJ, Sanna LJ, editors. Social Problem Solving: Theory, Research, and Practice. Washington, DC: American Psychological Association; 2006:117-134.

36. D'Zurilla TJ, Nezu AM, Maydeu-Olivares A. Social problem solving: theory and assessment. In: Chang EC, D'Zurilla TJ, Sanna LJ, editors. Social Problem Solving: Theory, Research, and Practice. Washington, DC: American Psychological Association; 2004:11-28.

37. Quittner AL, Drotar D, Ievers-Landis CE, Seidner D, Slockum N, Jackobsen J. Adherence to medical treatments in adolescents with cystic fibrosis: development and evaluation of family based interventions. In: Drotar D, editor. Promoting Adherence to Medical Treatment in Childhood Chronic Illness: Concepts, Methods, and Interventions. Mahwah, NJ: Erlbaum; 2000:383-408.

38. Wysocki T, Harris M, Greco P, et al. Randomized, controlled trial of behavior therapy for families of adolescents with insulin-dependent diabetes mellitus. J Pediatr Psychol. 2000;25(1):23-34.

39. Hill-Briggs F, Gemmell L. Problem solving in diabetes self-management and control: a systematic review of the literature. Diabetes Educ. 2007;33(6):1051-1052.

40. Modi AC, Guifoyle SM, Rausch J. Preliminary feasibility, acceptability, and efficacy of an innovative adherence intervention for children with newly diagnosed epilepsy. J Pediatr Psychol. 2013;38(6):605-616.

41. Wade SL, Stancin T, Kirkwood M, Brown TM, McMullen KM, Taylor HG. Counselor-assisted problem solving (CAPS) improves behavioral outcomes in older adolescents with complicated mild to severe TBI. $J$ Head Trauma Rehab. 2014;29(3):198-207.

42. Cook PF, Emiliozzi S, El-Hajj E, McCabe MM. Telephone nurse counseling for medication adherence in ulcerative colitis: a preliminary study. Patient Educ Couns. 2010;81(2):182-186.

43. Solomon MR. Information technology to support self-management in chronic care: a systematic review. Dis Manag Health Out. 2008;16(6):391-401.

44. Haskard Zolnierek KB, DiMatteo MR. Provider communication skills and patient adherence to treatment: a meta-analysis. Med Care. 2009;47:826-834.

45. Zolnierek KBH, DiMatteo MR. Physician communication and patient adherence to treatment: a meta-analysis. Med Care. 2009;47(8): 826-834.

46. Sewitch MA, Abrahamowicz M, Barkun A, Bitton A, Wild GE, Cohen A, Dobkin PL. Patient nonaderence to medication in inflammatory bowel disease. Am J Gastroenterol. 2003;98(7):1535-1544.

47. Plevinsky JM, Gumidyala AP, Fishman LN. Transition experience of young adults with inflammatory bowel diseases (IBD): a mixed methods study. Child Care Health Dev. 2015;41(5):755-761.

48. Kerse N, Buetow S, Mainous AG, Young G, Coster G, Arroll B. Physician-patient relationship and medication compliance: a primary care investigation. Ann Fam Med. 2004;2(5):455-461.

49. Sleath BL, Carpenter DM, Slota C, et al. Communication during pediatric asthma visits and self-reported asthma medication adherence. Pediatrics. 2012;130(4):627-633.

50. Thatcher Shope J. Medication compliance. Pediatr Clin North Am. 1981;28:5-21.

51. Kennedy A, Nelson E, Reeves D, et al. Disease management and patient satisfaction in inflammatory bowel disease. Health Technol Asses. 2003;7(28):1-113

52. Plener I, Hayward A, Saibil F. E-mail communication in the management of gastroenterology patients: a review. Can J Gastroenterol Hepatol. 2014;28(3):161-165.
53. DiMatteo MR. Social support and patient adherence to medical treatment: a meta-analysis. Health Psychol. 2004;23(2):207-218.

54. Moradkhani A, Beckman, LJ, Tabibian JH. Health-related quality of life in inflammatory bowel disease: psychosocial, clinical, socioeconomic, and demographic predictors. J Crohns Colitis. 2013;7(6):467-473.

55. van Groningen J, Ziniel S, Arnold J, Fishman LN. When independent health care behaviors develop in adolescents with inflammatory bowel disease. Inflamm Bowel Dis. 2012:18(12);2310-2314.

56. Reed-Knight B, Lewis JD, Blount RL. Association of disease, adolescent, and family factors with medication adherence in pediatric inflammatory bowel disease. J Pediatr Psychol. 2010;36(3):308-317.

57. Engstrom I, Lindquist BL. Inflammatory bowel disease in children and adolescents: a somatic and psychiatric investigation. Acta Paediatr Scand. 1991;80(6-7):640-647.

58. Nicholas DB, Otley A, Smith C, Avolio J, Munk M, Griffiths AM. Challenges and strategies of children and adolescents with inflammatory bowel disease: a qualitative examination. Health Qual Life Outcomes. 2007;5:28.

59. Janicke DM, Gray WN, Kahhan NA, Follansbee Junger KW, Marciel KK, Storch EA, Jolley CD. Brief report: the association between peer victimization, prosocial support, and treatment adherence in children and adolescents with inflammatory bowel disease. J Pediatr Psychol. 2008;34(7):769-773.

60. Saunders B. Stigma, deviance and morality in young adults' accounts of inflammatory bowel disease. Sociol Health Illn. 2014;36(7):1020-1036.

61. Taft TH, Ballou S, Keefer L. A preliminary evaluation of internalized stigma and stigma resistance in inflammatory bowel disease. $J$ Health Psychol. 2013;18(4):451-460.

62. Taft TH, Keefer L, Leonhard C, Nealon-Woods M. Impact of perceived stigma on inflammatory bowel disease patient outcomes. Inflamm Bowel Dis. 2009;15(8):1224-1232.

63. Strom JL, Egede LE. The impact of social support on outcomes in adult patients with type 2 diabetes: a systematic review. Curr Diab Rep. 2012;12(6):769-781.

64. Simoni JM, Frick PA, Huang B. A longitudinal evaluation of a social support model of medication adherence among HIV-positive men and women on antiretroviral therapy. Health Psychol. 2006;25(1):74-81.

65. Duncan TE, McAuley E. Social support and efficacy cognitions in exercise adherence: a latent growth curve analysis. J Behav Med. 1992;16(2):199-218.

66. Toljamo M, Hentinen M. Adherence to self-care and social support. $J$ Clin Nurs. 2001;10(5):618-627.

67. Dudley-Brown S. Prevention of psychological distress in persons with inflammatory bowel disease. Issues Ment Health Nurs. 2002;23(4):403-422.

68. Plevinsky JM, Greenley RN. Exploring health-related quality of life and social functioning in adolescents with inflammatory bowel diseases after attending Camp Oasis and participating in a Facebook group. Inflamm Bowel Dis. 2014;20(9):1611-1617.

69. Shepanski MA, Hurd LB, Culton K, Markowitz JE, Mamula P, Baldassano RN. Health-related quality of life improves in children and adolescents with inflammatory bowel disease after attending a camp sponsored by the Crohn's and Colitis Foundation of America. Inflamm Bowel Dis. 2005;11(2):164-170.

70. Salazar G, Heyman MB. Benefits of attending a summer camp for children with inflammatory bowel disease. $J$ Pediatr Gastroenterol Nutr. 2014;59(1):33-38.

71. Hogan BE, Linden W, Najarian B. Social support interventions: do they work? Clin Psychol Rev. 2002;22(3):383-442.

72. Kahana S, Drotar D, Frazier T. Meta-analysis of psychological interventions to promote adherence to treatment in pediatric chronic health conditions. J Pediatr Psychol. 2008;33(6):590-611.

73. Izaguirre MR, Keefer L. Development of a self-efficacy scale for adolescents and young adults with inflammatory bowel disease. $J$ Pediatr Gastroenterol Nutr. 2014;59(1):29-32.

74. Zullig LL, Peterson ED, Bosworth HB. Ingredients of successful interventions to improve medication adherence. JAMA. 2013;310(24):2611-2612. 
75. Bandura A. Self-efficacy: toward a unifying theory of behavioral change. Psychol Rev. 1977;84(2):191-215.

76. Plante WA, Lobato D, Engel R. Review of group interventions for pediatric chronic conditions. J Pediatr Psychol. 2001;26(7):435-453.

77. Ingerski L, Baldassano RN, Denson LA, Hommel KA. Barriers to oral medication adherence for adolescents with inflammatory bowel disease. J Pediatr Psychol. 2010;35(6):683-691.

78. Kurylo MF, Elliott TR, Schewchuck RM. FOCUS on the family caregiver: a problem-solving training intervention. J Couns Dev. 2001;79(3):275-281.

79. D'Zurilla TJ, Nezu AM. Development and preliminary evaluation of the social problem solving inventory (SPSI). Psychol. Assess. 1990;2(2):156-163.
80. Donovan JL, Blake DR. Patient non-compliance: deviance or reasoned decision-making. Soc Sci Med. 1992;34(5):507-513.

81. Ivey JB, Wright A, Dashiff CJ. Finding the balance: adolescents with type 1 diabetes and their parents. J Pediatr Health Care. 2009;23(1):10-18.

82. Sarason IG, Sarason BR, Shearin EN. A brief measure of social support. J Soc Pers Relationships. 1987;4:497-510.

83. Dibb B, Yardley L. Factors important for the measurement of social comparison in chronic illness: a mixed-methods study. Chronic Illn. 2006;2(3):219-230.

84. Mackner L, Crandall W. Psychological factors affecting pediatric inflammatory bowel disease. Curr Opin Pediatr. 2007;19(5):548-552.

85. Wu YP, Pai ALH. Health care provider-delivered adherence promotion interventions: a meta-analysis. Pediatrics. 2014;133(6):1698-1707.

\section{Clinical and Experimental Gastroenterology}

\section{Publish your work in this journal}

Clinical and Experimental Gastroenterology is an international, peerreviewed, open access, online journal publishing original research, reports, editorials, reviews and commentaries on all aspects of gastroenterology in the clinic and laboratory. This journal is included on PubMed. The manuscript management system is completely online

\section{Dovepress}

and includes a very quick and fair peer-review system, which is all easy to use. Visit http://www.dovepress.com/testimonials.php to read real quotes from published authors. 